\title{
Assessment of genetic diversity of cucumber cultivars in China based on simple sequence repeats and fruit traits
}

\author{
Y.T. Yang, Y. Liu, F. Qi, L.L. Xu, X.Z. Li, L.J. Cong, X. Guo, S.X. Chen and Y.L. Fang \\ Key Laboratory of Horticultural Plant Germplasm Resources Utilization in Northwest, \\ College of Horticulture Science, Northwest A\&F University, Yangling, Shaanxi, China \\ Corresponding authors: S.X. Chen / Y.L. Fang \\ E-mail: shuxiachen@nwsuaf.edu.cn / fangyulin@nwsuaf.edu.cn
}

Genet. Mol. Res. 14 (4): 19028-19039 (2015)

Received August 14, 2015

Accepted October 11, 2015

Published December 29, 2015

DOI http://dx.doi.org/10.4238/2015.December.29.10

\begin{abstract}
The cucumber (Cucumis sativus L.) is an important crop grown worldwide. In this study, the genetic diversity of 42 cucumber cultivars in China was analyzed using 51 pairs of simple sequence repeat (SSR) primers. These primers identified 129 polymorphic loci, 95.6\% of which were polymorphic. The mean effective number of alleles, mean Nei's gene diversity, and mean Shannon's information index were $0.36,0.16$, and 0.21 , respectively. A cluster analysis demonstrated that the 42 cultivars could be divided into three groups, a result that was largely consistent with those of a principal component analysis (PCA). The PCA indicated that the three groups displayed significant variation in fruit traits. The cultivars of group 1 tended to have longer fruits $(>30 \mathrm{~cm})$, longer fruit ends $(>4 \mathrm{~cm})$, larger fruit diameters $(>5 \mathrm{~cm})$, a sharp strigose fruit spine, and the same fruit end shape. The basal color of the fruit in group 2 was dark green. Group 3 cultivars have no wax or mottling on the fruit surface. Our study
\end{abstract}


demonstrates the value of our SSR primers for assessing genetic diversity in cucumber.

Key words: Cucumber; Cucumis sativus L.; Simple sequence repeat; Fruit traits; Genetic diversity

\section{INTRODUCTION}

The cucumber (Cucumis sativus L.) is an important and traditional vegetable crop that originated in tropical rainforests and is now grown worldwide (Huang et al., 2009). In China, the cucumber has been cultivated for more than 2000 years. Although the cucumber is produced using vegetative propagation, the species has substantial genetic diversity under different agroclimatic conditions (Innark et al., 2013). Some germplasms are well adapted to specific environments as a result of artificial and natural selection. Current clonal lineages display remarkable diversities in agricultural traits, including fruit color, fruit shape, fruit ribbing, fruit diameter, fruit skin glossiness, fruit spine color, fruit spine type, and stress resistance (Meglic and Staub 1996; Staub et al., 1997) This diversity in cucumber cultivars provides an important basis for the breeding of new varieties. Therefore, the assessment of germplasm resources is necessary to effectively use and cultivate cucumber plants (Innark et al., 2013). To date, such assessments have mainly relied on phenotypic analyses and have not considered the potential problem that the ecological environment might influence phenotypic expression. Thus, the analyses may not present an accurate reflection of genetic diversity among cultivars.

DNA markers are valuable tools for detection of genetic diversity among individuals or populations (Brookfield 1994). Various markers have been developed for this purpose, such as amplified fragment-length polymorphisms (AFLPs), sequence-related amplified polymorphisms (SRAPs), random amplified polymorphic DNA (RAPD), sequence characterized amplified regions (SCARs), sequence-tagged sites (STSs), simple sequence repeats (SSRs), and expressed sequence tag-SSRs (EST-SSRs) (Mliki et al., 2003; Devran et al., 2011; Hu et al., 2011; Zhang et al., 2012). These markers have been used to assess genetic diversity and relationships among cucumber cultivars, as they are not influenced by environmental conditions. Although some studies made use of one or more DNA markers (Danin-Poleg et al., 2001; Zhuang et al., 2004; Staub et al., 2005; Sikdar et al., 2010), few reports have examined the correlation between genetic diversity and agronomic traits, especially fruit traits.

The aim of this study was to assess genetic diversity among 42 cucumber cultivars and to establish the relationship between the markers and various agromorphological traits. The results of this assessment will provide information of value for cucumber breeders to produce high quality and high yield cucumber cultivars.

\section{MATERIAL AND METHODS}

\section{Plant material}

Forty-two cultivars from the cucumber germplasm nursery at the College of Horticulture, Northwest A\&F University were used in this research (Table 1). Plants were grown at the nursery between February and May 2012. Seeds were planted at a depth of $5 \mathrm{~cm}$, with row spacing of 40 $\mathrm{cm}$ and plant spacing of $25 \mathrm{~cm}$. 
Table 1. Description and grouping of qualitative characters of cucumber cultivars.

\begin{tabular}{|c|c|c|}
\hline Trait & Abbreviations & Classification \\
\hline Fruit basal color & SC & $\begin{array}{l}\text { Milky (1), Yellowish white (2), Whitish green (3), Light green (4), } \\
\text { green (5), Dark green (6), Black green (7) }\end{array}$ \\
\hline Fruit shape & $\mathrm{FC}$ & $\begin{array}{l}\text { Long club-shaped (1), Short club-shaped (2), } \\
\text { Long curved club-shaped (3), Short curved club-shaped (4), } \\
\text { Long cylindrical (5), Short cylindrical (6), Bee waist-shaped (7), } \\
\text { Spindle-shaped (8), Elliptical (9), Ovate (10), Obovoid (11), } \\
\text { Globose (12), Finger-shaped (13). }\end{array}$ \\
\hline Fruit length & $\mathrm{FL}$ & Fruit length in $\mathrm{cm}$; \\
\hline Fruit diameter & FD & Fruit diameter in $\mathrm{cm}$; \\
\hline Shape of fruit end & SFE & Bottle-neck (1), Inclined shoulder (2), Bluntly round (3) \\
\hline Length of fruit end & LFE & Length of fruit end in $\mathrm{cm}$ \\
\hline Fruit skin glossiness & FSG & Dull (1), Glossier (2), Glossy (3) \\
\hline Fruit ribbing & FR & Absent (1), Tiny (2), Intermediate (3), Prominent (4) \\
\hline Fruit surface wax & FSW & None (1), Sparse (2), Intermediate (3), Dense (4) \\
\hline Fruit mottling pattern & FMP & Absent (1), Dot (2), Longitudinal stripe (3), Block (4), Net (5) \\
\hline Distribution of fruit mottling & DFM & Absent(1), Fruit top (2), Partial fruit surface (3), Most fruit surface (4) \\
\hline Color of fruit mottling & CFM & Absent (1), White (2), Yellow (3), Green (4) \\
\hline Size of fruit warts & SFW & Absent (1), Small (2), Medium (3), Large (4). \\
\hline Density of fruit wart & DFW & Glabrous (1), Sparse (2), Medium (3), Dense (4) \\
\hline Color of fruit spine & CFS & Absent (1), White (2), Yellow (3), Gray brown (4), Brown (5), Black (6) \\
\hline Fruit spine type & FST & Sharp strigose (1), Pubescence (2), Grainy (3) \\
\hline
\end{tabular}

\section{DNA extraction}

Total DNA was extracted from young leaves at different stages based on the method of Chen et al. (2013). The purity of the recovered DNA was assessed using a NanoDrop2000 and agarose gel electrophoresis. The concentration of DNA was adjusted to $60 \mathrm{ng} / \mu \mathrm{L}$.

\section{SSR amplification}

Fifty-one SSR primers were used in the study (Table 2). SSR amplification was carried out as previously described by Cunha et al. (2012), with some modifications. The final volume of the reaction mixture was $11 \mu \mathrm{L}$, and included $60 \mathrm{ng}$ DNA, $6 \mu \mathrm{L}$ rTaq (Takara, Japan), $1 \mu \mathrm{L}$ each forward and reverse primer, and $2 \mu \mathrm{LddH} \mathrm{H}_{2} \mathrm{O}$. PCR conditions were as follows: $5 \mathrm{~min}$ at $94^{\circ} \mathrm{C}, 30 \mathrm{~s}$ at $94^{\circ} \mathrm{C}$, $45 \mathrm{~s}$ at $51^{\circ} \mathrm{C}$, and $60 \mathrm{~s}$ at $72^{\circ} \mathrm{C} ; 32$ cycles of $30 \mathrm{~s}$ at $94^{\circ} \mathrm{C}, 45 \mathrm{~s}$ at $51^{\circ} \mathrm{C}$, and $60 \mathrm{~s}$ at $72^{\circ} \mathrm{C}$; and a final extension for $10 \mathrm{~min}$ at $72^{\circ} \mathrm{C}$. PCR products were stored at $4^{\circ} \mathrm{C}$.

The PCR products were separated using PAGE with $6 \%$ denaturing gels in $1 \mathrm{X}$ TBE buffer at a constant $350 \mathrm{~V}$ for $3 \mathrm{~h}$. Bands were visualized using silver staining and photographed with a Panasonic DMC-T27 camera.

\section{Measurement of fruit traits}

Fifteen seedlings from each cultivar during the full fruit period were selected for observation and recording of fruit characteristics, namely color, shape, skin glossiness, end shape, mottling color, spine color, spine type, wart density, wart size, mottling distribution, mottling patterns, and ribbing. We also examined surface wax, length, diameter, and end length of the fruit. The fruits trait characteristics were determined subjectively (Table 1). 
Table 2. Sequences of SSR primers.

\begin{tabular}{|c|c|c|c|}
\hline Primer & Forward primer & Reverse primer & $\mathrm{Ta}\left({ }^{\circ} \mathrm{C}\right)$ \\
\hline 20993 & TCTCATTTAATCCСTTAGTTTTAAACAT & TGGTCAGTTGGTTACTTGGTCA & 50 \\
\hline 00193 & GCCAATCCAATGGAACAAGT & TTGTAAACCAAAACCTTACCCC & 50 \\
\hline 20704 & ATTGGCCGACCTTATCCTCT & GССТСТССТTTTССTCAАCC & 53 \\
\hline 06271 & TCGTGCTTCGTTCCATTTTTT & CCAATGTCATTTATTTACCCAAA & 50 \\
\hline 00084 & AAGTGTCAGCATGTCGTTCG & AAACGTCAGCCACACCTTTC & 50 \\
\hline 01012 & TCCAAAAATCGCGACCTAAA & GTGAGCCGTTGATTTCTCGT & 53 \\
\hline 17448 & TTTCAAAACGTATTATGCTTGTTAGC & ATTTGCTTGCATTTACCGGC & 50 \\
\hline 18141 & ATGTCAATATGTGGGACCCG & TCGTAATAAATGGATGGCCC & 50 \\
\hline 21456 & AAGTGGGAAGGTTTGGAGGT & ТTССТТТTТСССССТТСАТТ & 51 \\
\hline 12258 & GGTTCAAATTTCAAAGTGTATGAAT & GCCAAAGCTTCATAGTGAGCA & 50 \\
\hline 15755 & GTGCCTCAGTCGGTTTTGTT & GGGAGGGGAAGGATTCAAT & 50 \\
\hline 00231 & GAGGTTGGGAAATTGGGAAT & TATTCAAACACAAAGCCCGC & 53 \\
\hline 21834 & CCATTATAAATTGTTGGAGAGATTTT & GGGTGTTAGTTTCCAAAGGC & 50 \\
\hline 16841 & TTTGATGACAACAATCTTCATCG & CCTGTCGACAACATGGATTCT & 50 \\
\hline 22638 & TGTGTAAGATTTTTATTGGATGCC & CTGAGCTTGATCAATTCCTTCA & 50 \\
\hline 13504 & САТСССТТТТСССТТСТТСТTТ & TCCATGTGGAAGAATAACCCA & 53 \\
\hline 23220 & GTTTGCATGAAAATGGGGAT & CATCATCTTCTTGGTGGTTCC & 53 \\
\hline 21486 & GAAATCTGAAATATCAAGTGGAATTT & TTTAAAAGGCAAACGGCAAC & 55 \\
\hline 11512 & CCAAAAATCTTGCATTTTTTAGATCA & GGGTAATTCCCCATTGGTCA & 50 \\
\hline 13131 & AAAGCAGAGTATGGCATGGG & AAAAGCCAAAGAACCCAACA & 51 \\
\hline 28074 & CCCTAGATTGGCTGATCCTG & TCCCGAAATCTGTTCTACCG & 50 \\
\hline 07225 & TCCACGTCTTTTGTCTGGTG & TGACAGCGAATTATGAATAACAA & 50 \\
\hline 06650 & GCCCCCATGTTGTTGTTA & CAAAGCAAAGCAGCAAAGAA & 50 \\
\hline 10357 & AAGAAGTATGCGAGGTAAGGGA & GCCAGAAGTAAGAAGTGGTTGA & 50 \\
\hline 17389 & AAGGACAAAGACACATTAACAAAA & GGGTTCTACGAAGGAGAGCA & 53 \\
\hline 02674 & GGTGCATTGAAGCTGACGTA & AAGTACTCACAATTGGCGGC & 50 \\
\hline 05125 & TGGCTCCTTCACATTGTTGT & TGGGAAAAAGGGTATGGAAA & 53 \\
\hline 07269 & TTGATTCTACCATAGGACCTTCG & GGGGAGATAGGGGAGATGAA & 51 \\
\hline 03647 & TTAGGGCTCTGCTCCTTTCA & TAAAACGGGCAAACAGATCC & 51 \\
\hline 04245 & TGCTTCTGGGGAAATGACTT & GCAATTCCCGGACGTATATTT & 50 \\
\hline 19538 & TGCATGCAAAATAGGCAAGA & GCCCTGCAGTTTCTTCAGTC & 51 \\
\hline 02233 & GACGAAGAGACCGGATGGTA & GGCGGTTTTTACCCAAATCT & 53 \\
\hline 31415 & TAGTTTCACGTCCAATGCGA & CAATGGGATATCTGCATGACC & 53 \\
\hline 21219 & CCATTTCAATCCGCATAACC & CGCAATTGACGGCTATGTTA & 55 \\
\hline 20434 & CCAAATTAAAAGAATGATGGTGTG & CAACTAGGAAAATCCAACAAAA & 55 \\
\hline 05210 & TTTATGCCATTGTGCGTGAT & TCAAATCAACGTCAACCCAA & 50 \\
\hline 17962 & CAAAAGAAAAGCGCAAAAGG & GTCCСАСТСCСAAAAACAGA & 50 \\
\hline 33284 & TGGGAAATGGATAATTTGGTG & GGCATCCATCATTTCTTTGG & 50 \\
\hline 18405 & CGCAGGTGCATCTCATGTAA & GACAAACAAGGGGACGAAAA & 53 \\
\hline 20721 & AAGATGCATGGTGAAGAGGG & GGAGGTTGTTTGTTATGGTGG & 53 \\
\hline 12283 & GACAATTGATGTCCCATTACCA & GCAGCAAGAATCATGTCACC & 55 \\
\hline 11985 & GCTGCATTTCATTTAACGCTT & TGGTCCATCCTCACCAATTT & 53 \\
\hline 21936 & TTGGTTGGAAAAAGGAAGGTT & GGGCAGAGGCTTTTTCAATA & 50 \\
\hline 20583 & AACGTAATCGAAGGGTTGGA & CGCTTTAATTTTCAATGGGC & 50 \\
\hline 23250 & TTACСTСАСTTGССTCTGCC & TAAGGAATATGGTGGTGGGG & 50 \\
\hline 03083 & AAAAACTGCCAAAAGCCTAAA & TTCCATATGCATGCAAGCTC & 50 \\
\hline 19844 & ACCСАTСAАСССАТСAАСАТ & TGGAAGTTGAAAAATGGGAA & 50 \\
\hline 14257 & CGCGAAGAGTGTTTTAGTCTCA & TACAATGGGGCTATGGGAAC & 53 \\
\hline 15172 & GGTGTGGGTTATTTTGGCAC & GAAGAAATCAAAGAGGGGGC & 53 \\
\hline 11654 & AGACCCTTTCCAGGAACCAT & CAGAGGTGTCTAAGCTCCCG & 52 \\
\hline 11340 & ATATGTGTGTCGTGTTCCGC & CAGATTTCCGAGAGGGAAAA & 50 \\
\hline
\end{tabular}

\section{Statistical analysis}

For fruit traits, data are reported as means \pm standard deviations (SD) from three replicates and were analyzed using DPS v7.55 for Windows. Principal component analysis (PCA) was used to detect clustering and identify associations between cultivars and their fruit characteristics. For the molecular data, each polymorphic band was independently identified by two observers, and was scored as present (1) or absent (0). In the SSR analyses, the SSR bands of individual 
genotypes were recorded. These two matrices were then used for statistical analyses. The number of polymorphic loci (NPL), polymorphic information content (PIC), and percentage of polymorphic loci (PPL) were used to estimate the degree of polymorphism. PIC was calculated as described by Botstein et al. (1980) using the following equation:

$$
P I C=1-\sum_{i=1}^{k} P_{i}^{2}
$$

where " $k$ " is the total number of different alleles, and $P_{i}$ is the frequency of the "i" locus. The NTSYS-PC 2.2 software (Rohlf, 1992) was used to perform cluster analysis on the data in the similarity matrix, using the unweighted pair group method with arithmetic mean (UPGMA). The genetic diversity of SSRs was measured by Nei's gene diversity and Shannon's information index, and the effective number of alleles was estimated using the computer program POPGENE 1.32 (Yeh et al., 1999).

\section{RESULTS}

\section{SSR analysis}

Fifty-one pairs of SSR primers were used to screen three clusters displaying significantly different agricultural traits. The results of the SSR amplification and polymorphism analysis are given in Table 3. In total, 135 polymorphic loci were detected among the 42 cucumber cultivars, and the mean effective number of alleles, Nei's gene diversity, and Shannon's information index were $0.36,0.16$, and 0.21 , respectively.

\section{Cluster analysis}

A cluster analysis was used to calculate similarity coefficients as a measure of the genetic distance between the cultivars (Rohlf et al., 1992). For fruit traits, the similarity coefficients of the 42 cucumber germplasms varied from 0.24 to 0.88 , and the mean similarity coefficient of the 42 cucumber cultivars was 0.56 . A dendrogram analysis of the fruit data suggested that the cultivars could be divided into three groups: group 1 included 27 cultivars, group 2 included seven cultivars, and group 3 included eight cultivars (Figure 1). With a similarity coefficient level of 0.4 , group 1 could be further subdivided into two subgroups with one cultivar (G5-0) in the first subgroup and the other 26 cultivars in the second. Additionally, group 3 formed three subgroups at the same similarity coefficient level, with four cultivars (G38-1, G20, G17, and G36-1) in the first subgroup, two cultivars (WQ-6 and W7) in the second, and two cultivars (G33 and GQ-29) in the third. Group 2 could be divided into two subgroups at a similarity coefficient level of 0.46 . The first subgroup contained G32, WQ-8, W11-1, and G32, while the second contained cultivars W15, W14, G24, and G29.

In the SSR analysis, the mean similarity coefficient of the 42 cucumber cultivars was 0.76 (range, 0.64-0.89). A dendrogram analysis of the SSR data indicated that the 42 cucumber cultivars could be divided into three groups: group 1 consisted of 30 cultivars, group 2 consisted of 10 cultivars, and group 3 consisted of two cultivars (Figure 2). Using a coefficient of 0.7 , each 
of these three groups could be divided into several subgroups. Group 3 contained two subgroups, with W6-0 in the first subgroup and G17 in the other. Group 2 had three subgroups: G20, G21, G22, and G23 were in the first subgroup; G24, G28, G29, and G30 were in the second; and G31 and $\mathrm{G} 32$ were in the third.

\begin{tabular}{|c|c|c|c|c|c|}
\hline Primer & NPL & PIC & $N_{\mathrm{E}}$ & $\mathrm{H}$ & 1 \\
\hline 20993 & 2 & 0.3546 & 1.8088 & 0.4281 & 0.6157 \\
\hline 00193 & 4 & 0.5651 & 1.7427 & 0.2322 & 0.3414 \\
\hline 20704 & 3 & 0.5896 & 1.3164 & 0.4754 & 0.6683 \\
\hline 06271 & 2 & 0.3318 & 1.7071 & 0.2882 & 0.4560 \\
\hline 00084 & 4 & 0.6020 & 1.6442 & 0.3539 & 0.5199 \\
\hline 01012 & 2 & 0.3668 & 1.4449 & 0.4567 & 0.6487 \\
\hline 17448 & 2 & 0.3648 & 1.3273 & 0.4443 & 0.6353 \\
\hline 18141 & 2 & 0.3749 & 1.5429 & 0.4246 & 0.6154 \\
\hline 21456 & 7 & 0.5753 & 1.7611 & 0.1680 & 0.2944 \\
\hline 12258 & 2 & 0.3741 & 1.1721 & 0.4142 & 0.6046 \\
\hline 15755 & 4 & 0.5942 & 1.8221 & 0.3160 & 0.4875 \\
\hline 00231 & 2 & 0.2225 & 1.7628 & 0.2535 & 0.4146 \\
\hline 21834 & 3 & 0.5632 & 1.0504 & 0.3586 & 0.5408 \\
\hline 16841 & 2 & 0.3405 & 0.3134 & 0.3727 & 0.5545 \\
\hline 22638 & 2 & 0.2983 & 0.4603 & 0.3662 & 0.5456 \\
\hline 13504 & 2 & 0.3108 & 0.4031 & 0.3762 & 0.5580 \\
\hline 23220 & 2 & 0.2006 & 0.5232 & 0.2424 & 0.3985 \\
\hline 21486 & 3 & 0.5045 & 0.4212 & 0.3308 & 0.5092 \\
\hline 11512 & 2 & 0.3701 & 0.5408 & 0.2958 & 0.5532 \\
\hline 13131 & 3 & 0.5129 & 0.5545 & 0.3552 & 0.3979 \\
\hline 28074 & 4 & 0.6798 & 0.5456 & 0.1049 & 0.5962 \\
\hline 07225 & 2 & 0.2516 & 0.2690 & 0.2964 & 0.2963 \\
\hline 06650 & 2 & 0.3047 & 0.4577 & 0.2197 & 0.5171 \\
\hline 10357 & 3 & 0.2895 & 0.6122 & 0.3848 & 0.4374 \\
\hline 17389 & 3 & 0.5913 & 0.5629 & 0.1563 & 0.4729 \\
\hline 02674 & 2 & 0.1504 & 0.6931 & 0.3808 & 0.3432 \\
\hline 05125 & 2 & 0.3515 & 0.3613 & 0.2466 & 0.5623 \\
\hline 07269 & & Singleton variable sites & 1.3149 & 0.3244 & 0.0662 \\
\hline 03647 & 2 & 0.3750 & 0.6331 & 0.2452 & 0.2640 \\
\hline 04245 & & Singleton variable sites & 1.4231 & 0.2059 & 0.6788 \\
\hline 19538 & 2 & 0.3749 & 0.3926 & 0.3385 & 0.3520 \\
\hline 02233 & & Singleton variable sites & 1.7739 & 0.4296 & 0.5280 \\
\hline 31415 & 3 & 0.5563 & 1.2973 & 0.2424 & 0.4837 \\
\hline 21219 & 2 & 0.1217 & 1.9087 & 0.3695 & 0.4231 \\
\hline 20434 & 4 & 0.6798 & 1.4354 & 0.3074 & 0.2160 \\
\hline 05210 & 2 & 0.3725 & 1.6282 & 0.2649 & 0.4259 \\
\hline 17962 & 2 & 0.2843 & 1.8483 & 0.3073 & 0.5522 \\
\hline 33284 & 5 & 0.7407 & 1.3710 & 0.2235 & 0.4956 \\
\hline 18405 & 3 & 0.7368 & 1.3277 & 0.4112 & 0.3270 \\
\hline 20721 & 3 & 0.4479 & 1.7276 & 0.4113 & 0.2511 \\
\hline 12283 & 2 & 0.3749 & 1.6669 & 0.3797 & 0.5545 \\
\hline 11985 & 4 & 0.3804 & 1.4296 & 0.2390 & 0.6205 \\
\hline 21936 & 2 & 0.3725 & 1.3149 & 0.3695 & 0.4231 \\
\hline 20583 & 2 & 0.3363 & 1.2564 & 0.3083 & 0.4021 \\
\hline 23250 & 4 & 0.5640 & 0.4146 & 0.0121 & 0.4974 \\
\hline 03083 & 2 & 0.1766 & 1.6495 & 0.2816 & 0.4298 \\
\hline 19844 & 3 & 0.3894 & 1.4296 & 0.2390 & 0.6205 \\
\hline 14257 & 3 & 0.3894 & 0.5480 & 0.2999 & 0.2206 \\
\hline 15172 & 2 & 0.0905 & 1.0504 & 0.2958 & 0.5532 \\
\hline 11654 & 3 & 0.2356 & 1.1801 & 0.1435 & 0.2637 \\
\hline 11340 & 2 & 0.2688 & 1.5463 & 0.3302 & 0.5035 \\
\hline
\end{tabular}

$\mathrm{H}=$ Nei's gene diversity; I = Shannon's information index; $N_{\mathrm{E}}=$ effective number of alleles; $\mathrm{NPL}=$ number of polymorphic loci; PIC = polymorphic information content. 


\section{PCA}

A PCA was carried out using the combined raw data of the SSR matrix. The first six principal components contributed $65.6,79.2$, and $85.6 \%$ of the variation (Table 4 ). The 42 cucumber cultivars fell into three groups, with two cultivars in PCA group 1, 22 cultivars in PCA group 2, and 15 cultivars in PCA group 3 (Figures 2 and 3). An agromorphological trait matrix was also created which showed that the 42 cultivars could be divided into three groups, similarly to the results of UPGMA (Figure 3).

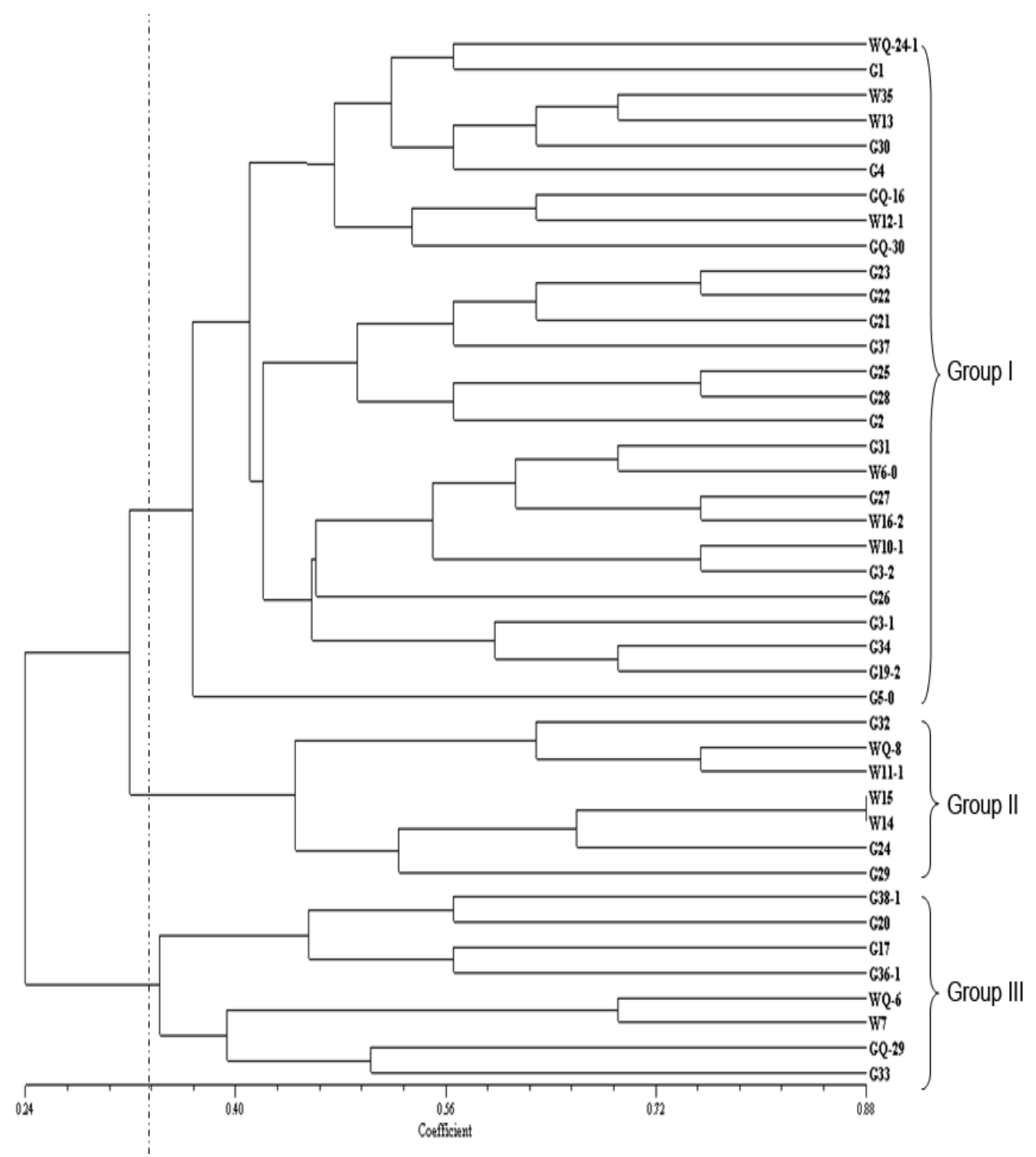

Figure 1. UPGMA dendrogram of the 42 cultivars of cucumber based on Nei's coefficients from fruit trait data. 


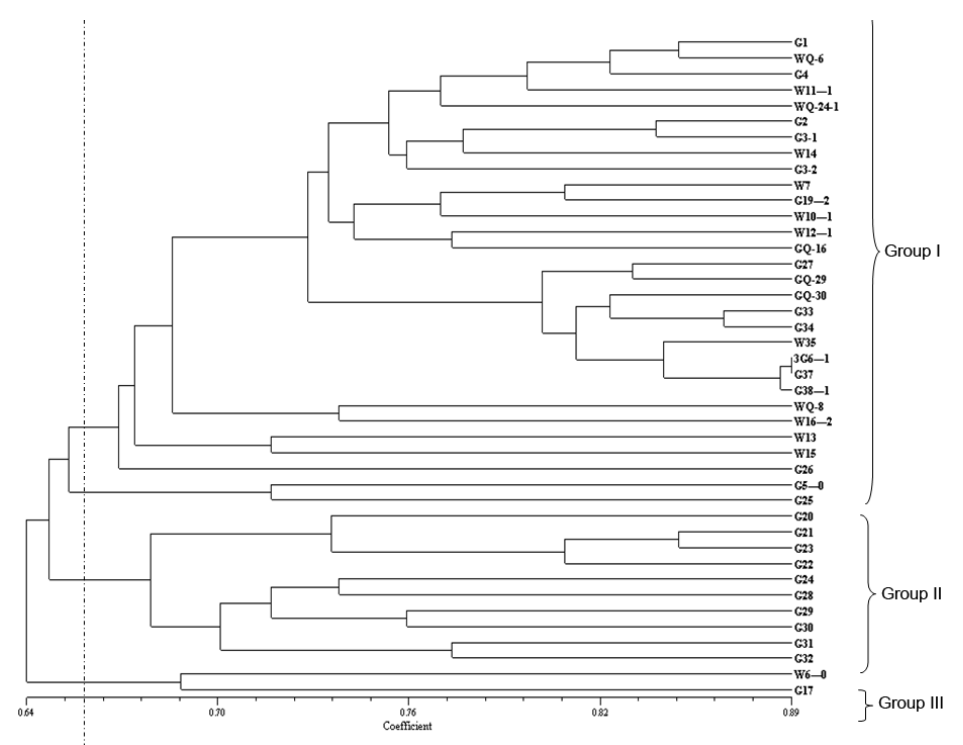

Figure 2. UPGMA dendrogram of the 42 cultivars of cucumber based on Nei's coefficients using SSR markers.

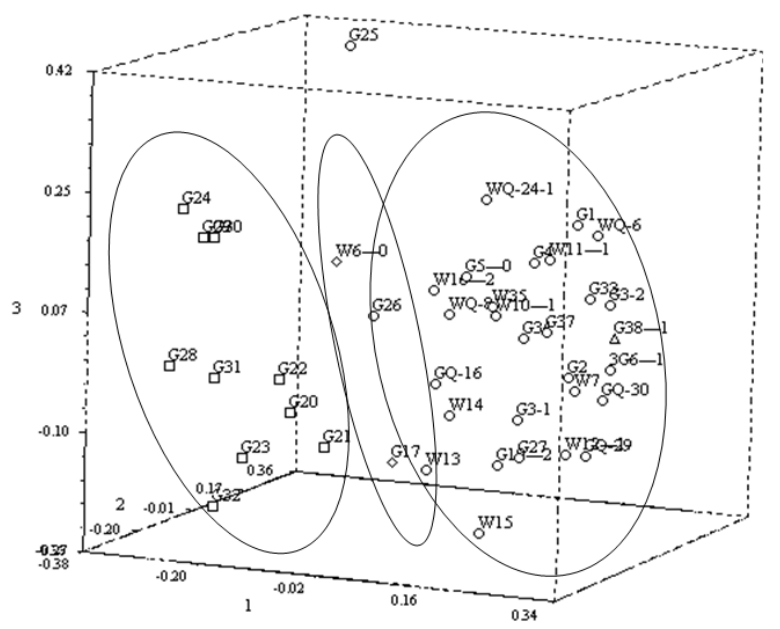

Figure 3. Plot of the principal components from analysis of SSR markers in the cucumber cultivars.

\section{Correlation between molecular markers and agromorphological traits}

The PCA was used to determine the associations between molecular markers and agromorphological traits. From this analysis, three groups were identified; the scatter plot of the PCA is shown in Figure 3 . In the zone with high positive values for PC2 and PC3, PCA group 2 exhibited similar fruit mottling patterns (0 or 2), mottling color (0 or 3), and mottling distribution ( 0 or 2), and the same basal color of the fruit (dark green), with the exception of G29 (Figures 3 and 
4; Tables 1 and 5). Additionally, most of the cultivars in PCA group 1 had longer fruit lengths ( $>30$ $\mathrm{cm}$ ) and fruit end lengths $(>4 \mathrm{~cm})$, larger fruit diameters $(>5 \mathrm{~cm})$, the same fruit spine type (sharp strigose), and the same fruit end shape. PCA group 3, which included G17 and W6-0, had fruits with no waxing or mottling of the surfaces.

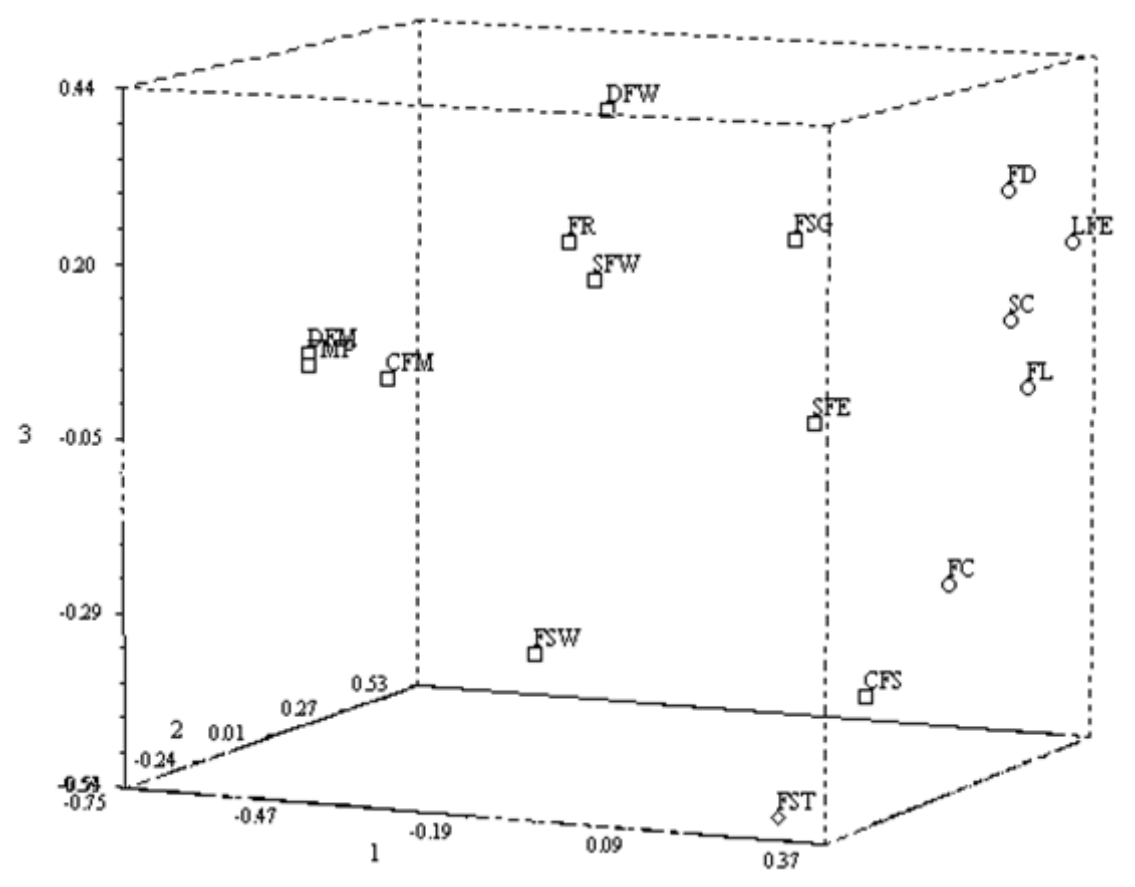

Figure 4. Plot of the principal components from analysis of fruit traits in the cucumber cultivars.

\begin{tabular}{|c|c|c|c|}
\hline X loadings & PC-1 & PC-2 & PC-3 \\
\hline Cumulative proportion of variation (\%) & 65.6425 & 79.2103 & 85.6162 \\
\hline SC & 5.5137 & 1.2316 & 3.9013 \\
\hline $\mathrm{FC}$ & 5.0374 & 7.096 & -0.1321 \\
\hline $\mathrm{FL}$ & 8.8504 & -4.4816 & 0.0947 \\
\hline FD & 8.4206 & 1.219 & -4.0849 \\
\hline SFE & -0.1274 & 1.4962 & -0.8158 \\
\hline LFE & 9.3763 & -3.1393 & 0.8572 \\
\hline FSG & -2.1125 & 0.0222 & -0.013 \\
\hline FR & -3.7622 & 0.5103 & 0.8541 \\
\hline FSW & -3.8587 & 0.1792 & -0.1912 \\
\hline FMP & -5.334 & -1.0765 & -0.8999 \\
\hline DFM & -5.2164 & -1.1183 & -0.9548 \\
\hline CFM & -4.5434 & -1.3728 & -1.4211 \\
\hline SFW & -3.8641 & 0.0937 & 1.0488 \\
\hline DFW & -2.92 & 0.5535 & 1.7894 \\
\hline CFS & -2.7507 & -0.6432 & 0.6562 \\
\hline FST & -2.709 & -0.5702 & -0.6888 \\
\hline
\end{tabular}

Abbreviations are explained in Table 1. 


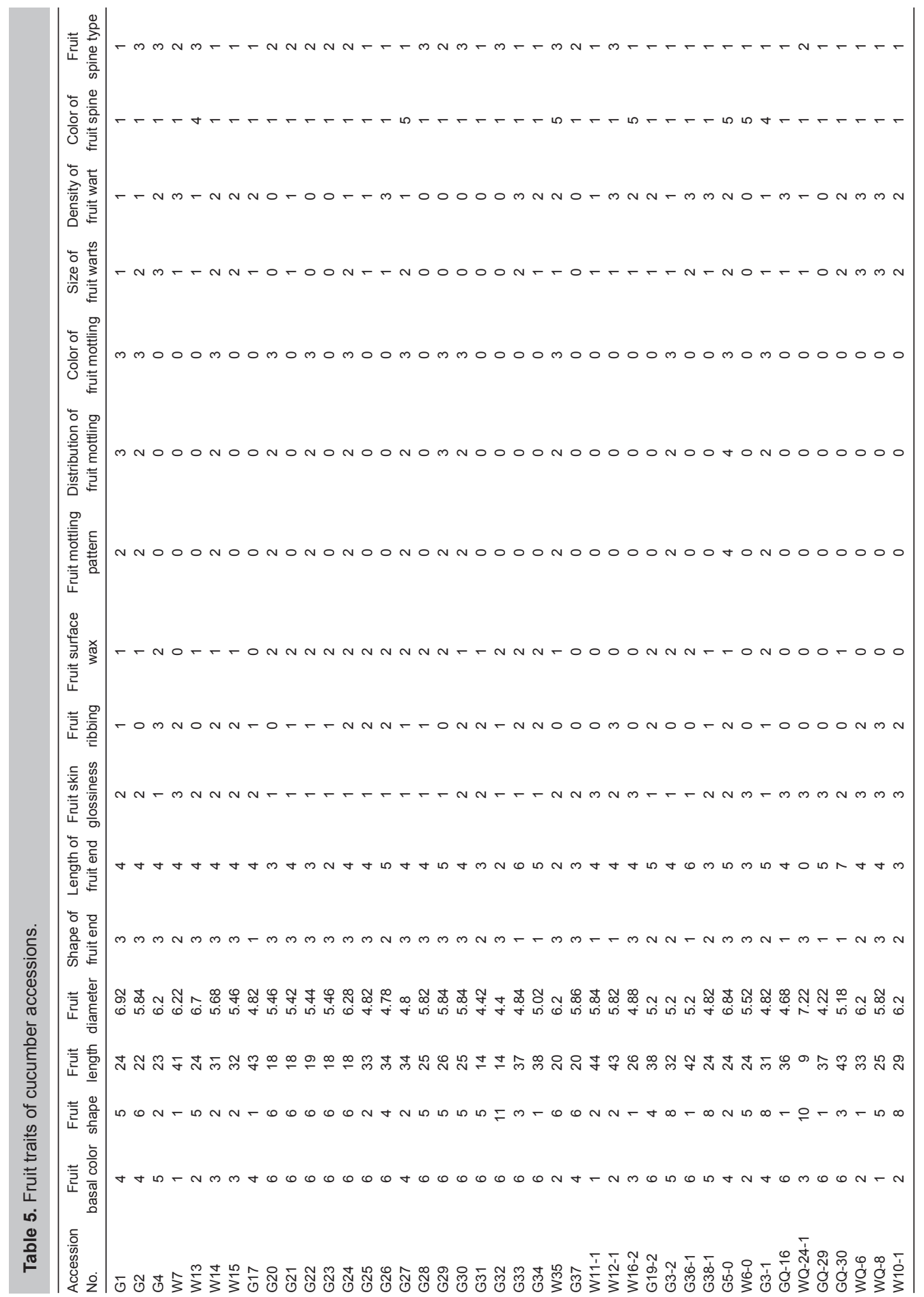




\section{DISCUSSION}

In this study, the genetic diversity of 42 cucumber cultivars was estimated and the relationship between molecular marker data and fruit traits was examined. Our PCA revealed significant association between molecular marker data and fruit traits. These results will provide valuable information for cucumber breeders striving to produce new high-quality and high-yield cucumber cultivars.

In a previous study, SSRs were used to assess genetic diversity. In the study of Kong et al. (2014), 80 SSR markers were used to determine the genetic diversity and relationships of 35 Cucurbita rootstock accessions. And the result showed that some of polymorphic SSR markers provided comprehensive assessment on the genetic variations of the Cucurbita rootstock germplasm. Levi et al. (2001) reported that SSR analysis of Iranian melon cultivars show they have wide genetic distance. 70 SSR markers coupled with 10 morphological traits were used to analysis the genetic diversity of 44 cucumber accessions, which provide useful information for future exploration of cucumber germplasm (Ren et al., 2009; Pandey et al., 2013). The current study used 51 SSR primers to detect genetic diversity; our results suggested that significant variation in mean effective number of alleles, mean Nei's gene diversity, and mean Shannon's information index were present in the examined cultivars.

However, from the genetic analysis here, some cultivars were included in the same group even when they showed no similarities for particular fruit traits. Thus, there were inconsistencies among the outcomes of the analyses of molecular markers and of agromorphological traits. These inconsistencies were also observed in a previous study on garlic (Chen et al., 2014). There are three possible explanations for this phenomenon. First, the classification of economic characteristics is artificial; second, only a few main traits were used for analysis; third, the controlling of fruit basal color is a quantitative genetic trait that is susceptible to environmental influences (our unpublished data). Further studies are required to fully elucidate the relationships between genetic markers and morphological traits.

Molecular markers are a more reliable method for analysis of genetic diversity than agromorphological traits, and accurate analysis of the association between the two methods would provide substantial aid to plant breeding and cultivation techniques. Our research using DNA markers suggested that the cucumber exhibits genetic diversity (Mliki et al., 2003) and that there is an important relationship between DNA markers and certain fruit traits. Cluster analysis revealed that the cultivars could be divided into three groups based on fruit traits, and that this grouping was largely consistent with that obtained by PCA.

In conclusion, this study analyzed genetic diversity in 42 cucumber cultivars and identified a correlation between molecular markers and fruit traits. These results will be useful for future programs to develop new cucumber cultivars and will facilitate further studies into cucumber genetics and development.

\section{Conflicts of Interest}

The authors declare no conflict of interest.

\section{ACKNOWLEDGMENTS}

Research supported by grants from the Yulin City Science and Technology Bureau Project and the National Public Welfare Research Project (grant \#200903018-7). 


\section{REFERENCES}

Botstein D, White RL, Skolnick M and Davis RW (1980). Construction of a genetic linkage map in man using restriction fragment length polymorphisms. Am. J. Hum. Genet. 32: 314-331.

Chen SX, Zhou J, Chen Q, Chang YX, et al. (2013). Analysis of the genetic diversity of garlic (Allium sativum L.) germplasm by SRAP. Biochem. Syst. Ecol. 50: 139-146.

Chen SX, Chen WF, Shen XQ, Yang YT, et al. (2014). Analysis of the genetic diversity of garlic (Allium sativum L.) by simple sequence repeat and inter simple sequence repeat analysis and agro- morphological traits. Bioche. Syst. Ecol. 55: 260-267.

Cunha CP, Hoogerheide ESS, Zucchi MI, Monteiro M, et al. (2012). New microsatellite markers for garlic, Allium sativum L. (Alliaceae). Am. J. Bot. 99: e17-e19.

Danin-Poleg Y, Reis N, Tzuri G and Katzir N (2001). Development and characterization of microsatellite markers in Cucumis. Theor. Appl. Genet. 102: 61-72.

Devran Z, Firat AF, Tor M, Mutlu N, et al. (2011). AFLP and SRAP markers linked to the mj gene for root-knot nematode resistance in cucumber. Sci. Agric. 68: 115-119.

Hu J, Wang L and Li J (2011). Comparison of genomic SSR and EST-SSR markers for estimating genetic diversity in cucumber. Biol. Plantarum 55: 577-580.

Huang SW, Li RQ, Zhang ZH, Li L, et al. (2009). The genome of the cucumber, Cucumis sativus L. Nat. Genet. 41: 1275-1281.

Innark P, Khanobdee C, Samipak S and Jantasuriyarat C (2013). Evaluation of genetic diversity in cucumber (Cucumis sativus L.) germplasm using agro-economic traits and microsatellite markers. Sci. Hortic.-Amsterdam 162: 278-284.

Kong QS, Chen JL, Liu Y, Ma YH, et al. (2014). Genetic diversity of cucurbita rootstock germplasm as assessed using simple sequence repeat markers. Sci. Hortic.-Amsterdam 175: 150-155.

Levi A, Thomas CE, Keinath AP and Wehner TC (2001). Genetic diversity among watermelon (Citrullus lanatus and Citrullus colocynthis) accessions. Genet. Resour. Crop Ev. 48: 559-566.

Meglic V and Staub JE (1996). Genetic diversity in cucumber (Cucumis sativus L). II. An evaluation of selected cultivars released between 1846 and 1978. Genet. Resour. Crop Ev. 43: 547-558.

Mliki A, Staub JE, Sun ZY and Ghorbel A (2003). Genetic diversity in African cucumber (Cucumis sativus L.) provides potential for germplasm enhancement. Genet. Resour. Crop Ev. 50: 461-468.

Pandey S, Ansar WA, Mishra VK, Singh AK, et al. (2013). Genetic diversity in Indian cucumber based on microsatellite and morphological markers. Biochem. Syst. Ecol. 51: 19-27.

Ren Y, Zhang ZH, Liu JH, Staub JE, et al. (2009). Integrated genetic and cytogenetic map of the cucumber genome. PloS One 4: e5795.

Rohlf JH. (1992) NTSYS-pc: Numberical Taxonomy and Multivariate Analysis System, version 2.2. Exter software, Setauket, New York.

Sikdar B, Bhattacharya M, Mukherjee A, Banerjee A, et al. (2010). Genetic diversity in important members of Cucurbitaceae using isozyme, RAPD and ISSR markers. Biol. Plantarum 54: 135-140.

Staub JE, Serquen FC and McCreight JD (1997). Genetic diversity in cucumber (Cucumis sativus L). III. An evaluation of Indian germplasm. Genet. Resour. Crop Ev. 44: 315-326.

Staub JE, Chung SM and Fazio G (2005). Conformity and genetic relatedness estimation in crop species having a narrow genetic base: the case of cucumber (Cucumis sativus L.). Plant Breeding 124: 44-53.

Zhang WW, Pan JS, He HL, Zhang C, et al. (2012). Construction of a high density integrated genetic map for cucumber (Cucumis sativus L.). Theor. Appl. Genet. 124: 249-259.

Zhuang FY, Chen JF, Staub JE and Qian CT. (2004). Assessment of genetic relationships among spp. by SSR and RAPD marker analysis. Plant Breeding 123:167-172.

Yeh FC, Yang R and Boyle T (1999). POPGENE Version 1.32: Microsoft-based freeware for population genetics analysis. University of Alberta, Edmonton, $A B$, Canada. 